\title{
Platelet-Rich Fibrin Enhances Fracture Healing in Tibial Long Bone: An Experiment in Rabbit
}

\author{
Nucki Nursjamsi Hidajat, Dicky Mulyadi, M. Rizal Chaidir, Taufan Herwindo Dewangga \\ Department of Orthopaedic and Traumatology Faculty of Medicine Universitas Padjadjaran \\ Dr. Hasan Sadikin General Hospital Bandung, Indonesia
}

\section{Abstract}

Background: Fracture on long bone is a complicated case to manage. Bone graft procedure involving growth factors has been widely studied with promising results. Recently, platelet-rich fibrin (PRF) has been introduced as having potential in healing process. This study aimed to explore the quality of fracture healing on long bones treated with bone graft with and without PRF combination.

Methods: This study was conducted between October to November 2018 on 18 rabbits that were divided into 2 groups. A $5 \mathrm{~mm}$ fracture was created on tibial bones and the fracture was stabilized using a $2.0 \mathrm{~mm}$ mini plate. The defect was then treated by an autogenic bone graft with and without PRF. Histological analysis was conducted 3 weeks after the treatment and a scoring was performed using the Salkeld system. The quality of union; cortex development and remodeling; and bone graft incorporation and new bone formation were then analyzed.

Results: There were significant differences between fractures in rabbits given PRF than those without

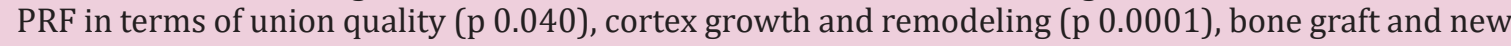
bone union ( $\mathrm{p}$ 0.0001), as well as in the total Salkeld score ( $\mathrm{p}$ 0.0001).

Conclusions: PRF given with bone graft therapy can enhance the quality of fracture healing of a long bone. Further studies on how the PRF content influences fracture healing process needs to be performed to further explore this effect.

Keywords: Bone graft, defect fracture, platelet rich fibrin

\section{Introduction}

Defect fracture is a fracture characterized by loss of part of the diaphyseal bone fragment. The defect cannot be healed without operative intervention with a bone graft or with the osteogenesis distraction method. High energy trauma, tumor resection, surgery revision, bone development impairment, and infection can cause a large bone defects with few healing potentials. Bone defect cases in Hasan Sadikin General Hospital were reported about 447 cases in $2007 .^{1,2}$

The combination of mechanical and biological techniques to shorten the healing process of bone defect has been studied recently. Bone graft, involving the use of growth factors, platelet-rich plasma, and platelet-derived growth factors, has shown promising results. ${ }^{3,4}$ Platelet rich fibrin (PRF) has been the focus of recent studies for its potential in accelerating the healing process. PRF excels more than PRP in terms of growth factors secretion that is more relatively consistent with longer duration and also its ease to obtain. ${ }^{5}$ This study aimed to determine the quality of defect fracture healing on long bone histologically, on subjects treated with bone graft with and without the combination of PRF.

\section{Methods}

This study was an experimental study with a completely randomized design. The subjects of the study were 18 adult male rabbits, aged 24 months, weighted 3-4 kilograms, and healthy. Rabbits that were ill had anatomical defects, and had weight loss more than $10 \%$ off initial weight were excluded. The infected

Correspondence: Taufan Herwindo Dewangga, Department of Orthopaedic and Traumatology Faculty of Medicine, Universitas Padjadjaran/Dr. Hasan Sadikin General Hospital, Jalan Pasteur No. 38, Bandung, Indonesia, E-mail: taufanhdewangga@gmail.com 


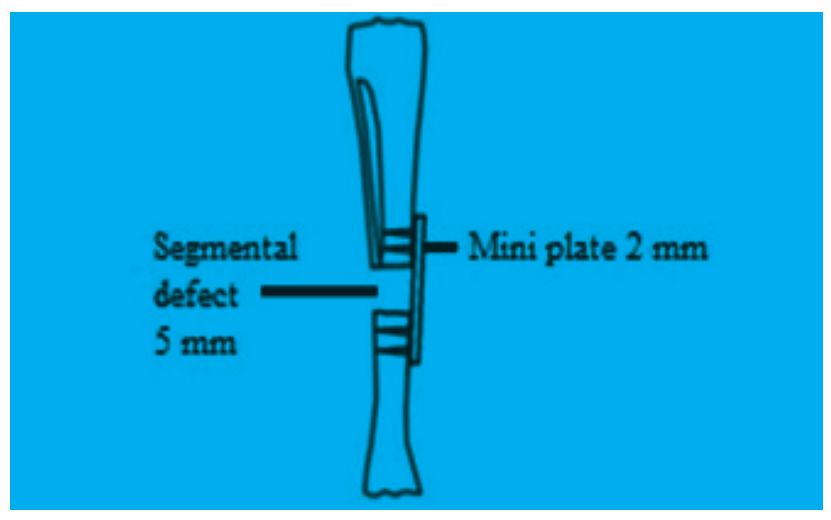

Figure 1 Rabbit Bone Tibial Bone Segmental Defect Fixation using a Miniplate

or dead rabbit was dropped out of the study.

The study was conducted in Pharmacology and Therapy Laboratory of Universitas Padjadjaran in collaboration with the Department of Anatomical Pathology, Dr. Hasan Sadikin General Hospital, from October-November 2018 after approval was released from Department of Orthopaedic and Traumatology and the Research Ethics Committee Dr. Hasan Sadikin General Hospital (no. LB.02.01/X.2.2.1/19761/2018).

Eighteen male rabbits were divided into 2 groups, a group with segmental fracturization on the tibia and treated with an autogenic bone graft (group K-1) and a group with segmental fracturization on the tibia and treated with autogenic bone graft and PRF (K-2). There was 1 week of adaptation process for the rabbits to be familiar with the study environment.

This study consisted of 3 steps, first was bone fracturization and then stabilization with plate and screw; the second was autogenic bone graft, third was an addition of PRF to the K-2 group. In brief, the subject was anesthetized by ketamine hydroxychloride $50 \mathrm{mg} / \mathrm{kg}$ body weight intramuscular with diazepam $5 \mathrm{mg} / \mathrm{Kg}$ body weight. The hair on the front lower leg was cut and given antiseptic. The incision was made until the bone was exposed. The bone segment was cut $5 \mathrm{~mm}$ at the middle part of the tibia using an oscillator knife. Washing using physiological saline was done to prevent osteonecrosis. The fracture fragment was fixated using miniplate $(2.0 \mathrm{~mm})$ and 4 screws on the subject's tibia. The average thickness of human's cortical bone is 10 times bigger than average cortical bones of rabbit. The bone segment was cut $5 \mathrm{~mm}$ on this study with the analogy of $5 \mathrm{~cm}$ segmental defect on human's tibial bone. ${ }^{6}$

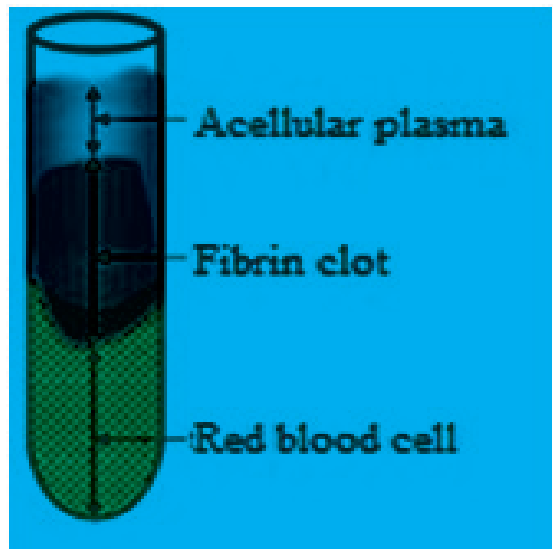

Figure 2 Fibrin Clot between Acellular Plasma and Red Blood Cell after Centrifugation ${ }^{8}$ 
Table 1 Salkeld Scoring System ${ }^{9}$

\begin{tabular}{|c|c|c|}
\hline & Description & Grade \\
\hline \multicolumn{3}{|l|}{ Quality of union } \\
\hline & - No sign of fibrous or other unions & 0 \\
\hline & - Fibrous union & 1 \\
\hline & - Fibrocartilaginous union or cartilage union & 2 \\
\hline & - Mineralizing cartilage and bone union & 3 \\
\hline & - Bone union & 4 \\
\hline \multicolumn{3}{|c|}{ Cortex development and remodeling } \\
\hline & - No cortex formed & 0 \\
\hline & - Densification of new bone along exterior borders & 1 \\
\hline & $\begin{array}{l}\text { Recognizable formation of both the outer cortex } \\
\text { border and the medullary space }\end{array}$ & 2 \\
\hline & - Cortices formed but incomplete bridging & 3 \\
\hline & $\begin{array}{l}\text { - Complete formation of cortices with the bridging of } \\
\text { the defect }\end{array}$ & 4 \\
\hline \multicolumn{3}{|c|}{ Bone-graft incorporation and new-bone formation } \\
\hline \multirow[t]{3}{*}{$\begin{array}{l}\text { - No new bone, all or most of } \\
\text { graft visible }\end{array}$} & $\begin{array}{l}\text { - Graft material present, no incorporation, and no new- } \\
\text { bone formation }\end{array}$ & 0 \\
\hline & $\begin{array}{l}\text { Graft present, some incorporation with new-bone } \\
\text { formation, and a small amount of new bone }\end{array}$ & 1 \\
\hline & $\begin{array}{l}\text { - Graft present, some incorporation with new-bone } \\
\text { formation, and a moderate amount of new bone }\end{array}$ & 2 \\
\hline \multirow[t]{3}{*}{$\begin{array}{l}\text { - Decreasing graft, increasing } \\
\text { new bone }\end{array}$} & $\begin{array}{l}\text { Graft present, some incorporation with new-bone } \\
\text { formation continues with host bone, and early } \\
\text { remodeling changes in new bone }\end{array}$ & 3 \\
\hline & $\begin{array}{l}\text { - Decreased amount of graft (compared with grade 3), } \\
\text { good graft incorporation, and ample new bone }\end{array}$ & 4 \\
\hline & $\begin{array}{l}\text { Less amount of graft still visible (compared with } \\
\text { garde 4), good incorporation of graft and new bone } \\
\text { with host and ample new bone }\end{array}$ & 5 \\
\hline $\begin{array}{l}\text { - No graft visible, extensive } \\
\text { new bone }\end{array}$ & $\begin{array}{l}\text { Difficult to differentiate graft from new bone, } \\
\text { excellent incorporation, and advanced remodeling of } \\
\text { new bone with graft and host }\end{array}$ & 6 \\
\hline
\end{tabular}

The second step was the use of an autogenic bone graft from $5 \mathrm{~mm}$ bone that was obtained from the making of the defect itself. This whole bone segment was crushed into smaller pieces to make it easier for grafting. The last step was the addition of PRF for the second group. Autologous PRF was prepared from $8 \mathrm{ml}$ of arterial blood from the central artery of the rabbit's ear before sedation. A blood sample without anticoagulant was collected onto a 10 $\mathrm{ml}$ glass tube and centrifugated at $3000 \mathrm{rpm}$ for 10 minutes. The fibrin clot in the middle part of the tube was the one used for graft material. $^{7}$
The surgical wound was then closed by suture with catgut on $3 / 0$ and the subject was given cefazoline $30 \mathrm{mg} / \mathrm{Kg} \mathrm{BW} /$ day intramuscular on thigh's muscle 2 times a day, alternating right and left, for 3 days. A tibial bone sample was obtained 3 weeks after surgery for histologic evaluation. The Tibial bone was brought in formalin liquid to the Department of Anatomical Pathology, Dr. Hasan Sadikin General Hospital. Histologic evaluation was performed using Salkeld Scoring System by a pathologist consultant to minimize possible bias. 

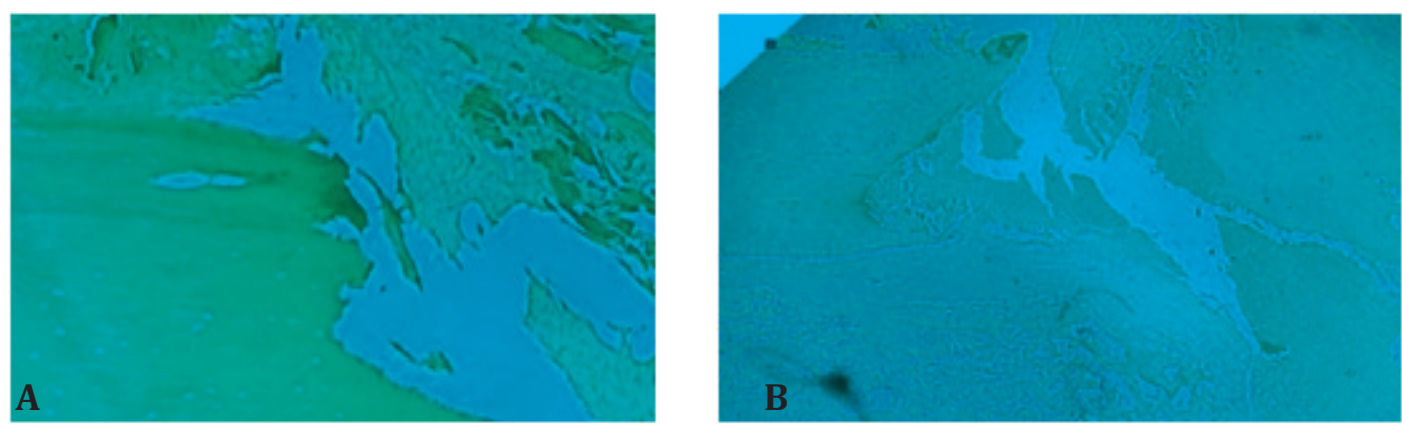

Figure 3 A. Histological Appearance of Group 1 with Score 1, B. Histological Appearance of Group 2 with Score 5

\section{Results}

Group 1 had 4 samples as a control group with a score 1. Histological appearance demonstrated signs of fibrous union (Figure 3A). Furthermore, group 1 had 5 samples with score 2 that had signs of fibrocartilaginous union or cartilage.

Group 2 had 5 samples with a score 5 . Histological appearance with score 5, demonstrated signs of fibrocartilaginous or cartilage union,

Table 2 Score of Group 1 and 2 based on the Salkeld Scoring System

\begin{tabular}{lcccc}
\hline Sample number & Union quality & $\begin{array}{c}\text { Cortex } \\
\text { development and } \\
\text { remodeling }\end{array}$ & $\begin{array}{c}\text { Bone-graft } \\
\text { incorporation and } \\
\text { new-bone formation }\end{array}$ & $\begin{array}{c}\text { Total Salkeld score } \\
\text { point* }\end{array}$ \\
\hline Group 1 & 1 & - & - & 1 \\
1 & 2 & - & - & 2 \\
2 & 1 & - & - & 1 \\
3 & 2 & - & - & 2 \\
4 & 2 & - & - & 2 \\
5 & 2 & - & - & 2 \\
6 & 1 & - & - & 1 \\
7 & 1 & - & - & 1 \\
8 & 2 & - & - & 2 \\
9 & & & & 4 \\
Group 2 & 1 & 1 & 5 \\
1 & 2 & 1 & 1 & 4 \\
2 & 3 & 1 & 1 & 4 \\
3 & 2 & 1 & 1 & 5 \\
4 & 2 & 2 & 1 & 5 \\
5 & 2 & 2 & 1 & 5 \\
6 & 2 & 1 & 1 & 4 \\
7 & 3 & 2 & 1 & 5 \\
8 & 2 & & & 5 \\
9 & 2 & & & 5 \\
\hline
\end{tabular}

Note: Total Salkeld score point 3 weeks post-operation 
Table 3 Comparison of Union Quality, Cortex Development and Remodeling, Bone-graft Incorporation and New-bone Formation, and Total Salkeld Score Point 3 Weeks Post-operation between Group 1 and 2

\begin{tabular}{|c|c|c|c|}
\hline \multirow{3}{*}{ Variable } & \multicolumn{2}{|c|}{ Group } & \multirow{3}{*}{ P-value } \\
\hline & $\mathbf{I}$ & II & \\
\hline & $\mathrm{N}=9$ & $\mathrm{~N}=9$ & \\
\hline Union quality & & & $0.040^{* *}$ \\
\hline Median & 2.00 & 2.00 & \\
\hline Range (min-max) & $1.00-2.00$ & $2.00-3.00$ & \\
\hline Cortex development and remodeling & & & $0.0001^{* *}$ \\
\hline Median & 0.00 & 1.00 & \\
\hline Range (min-max) & 0.00 & $1.00-2.00$ & \\
\hline $\begin{array}{l}\text { Bone-graft incorporation and new-bone } \\
\text { formation }\end{array}$ & & & $0.0001^{* *}$ \\
\hline Median & 0.00 & 1.00 & \\
\hline Range (min-max) & 0.00 & 1.00 & \\
\hline Total Salkeld score point 3 weeks post-operation & & & $0.0001^{* *}$ \\
\hline Mean \pm SD & $1.55 \pm 0.527$ & $4.55 \pm 0.527$ & \\
\hline Median & 2.00 & 5.00 & \\
\hline Range (min-max) & $1.00-2.00$ & $4.00-5.00$ & \\
\hline
\end{tabular}

densification of new bone along outer margin, and graft material slightly united with new bone development, and few new bone formation (Figure $3 \mathrm{~B}$ ).

The comparison between group 1 and group 2 in terms of union quality, cortex development and remodeling, bone-graft incorporation and new-bone formation, and numerical data of total Salkeld score point 3 weeks post-operation, all resulted in p-value $<0.05$, which was significant, suggesting that PRF addition to autologous bone graft therapy could enhance the quality of long bone defect fracture healing histologically.

\section{Discussion}

This study has analyzed callus formation using the histological examination. However, the method might have some drawbacks regarding subjectivity from the pathologist, which can be minimized by using a scoring system that is Salkeld scoring system. The result of this study has shown a significant difference between the group that has been treated with only autologous bone graft and the group treated with autologous bone graft and with the addition of PRF. The PRF has a positive effect on new bone formation on calvarial bone or flat bone when used either alone or combined with bone graft. The effect of PRF on periodontal defect has a better effect on the periodontal defect. Our study has a better study period, which is for 3 weeks. Callus formation is predicted to happen in the second up to the third week. Differentiation of stem cells into chondrogenic and osteogenic cells might occur in the third week, creating a biological environment that is optimum for new bone formation. ${ }^{10-12}$

This study used cortical bone graft as material to fill the bone defect because long bone defect fracture needs firm structural support that could not be fulfilled by a cancellous bone graft. The synthetic bone graft is not chosen because of the extra cost needed and the possibility of immunological rejection. The slower rate of union between cortical bone grafts with host bone could show the acceleration effect of bone healing after PRF addition in this study.

The PRF is a natural reservoir for growth 
factors, forming a solid fibrin matrix, PRF is obtained by centrifugation blood that has been taken without anticoagulant. It works by slowreleasing several growth factors necessary in regulating proliferation, migration, mesenchymal cell growth. ${ }^{15}$

Ling et al. ${ }^{16}$ compared the effect of PRP and PRF on the proliferation and differentiation process of osteoblast in mouse samples, showing that PRF is better than PRP because PRF is a slow-released autologous growth factor. PRF demonstrates a better and more durable effect on cell proliferation and differentiation, and it is formed from a natural and progressive polymerization during centrifugation. This relatively slow and progressive polymerization could increase cytokine binding onto fibrin mesh. Many PDGF and TGF contained PRF especially on day 14 may then slowly decrease. The autologous growth factor could influence cells for 5-7 days. This dissolved molecule is believed to be bound on PRF fibrin mesh and could go off controllably and has a relatively long effect. It is caused by an abundant amount of fibrin on PRF that could prevent proteolytic degradation of the growth factors. Stages of bone healing with a bone graft that consist of inflammation, osteoblast differentiation, osteoinduction, osteoconduction, and remodeling occur at the first 14 days after bone graft insertion, hence, PRF stimulates bone regeneration well. ${ }^{16}$

However, Faot et al. ${ }^{17}$ have a different result from the previous study, showing that PRF does not increase bone healing on rabbit tibial bone defect fracture. There are several flaws from his study, such as no stable fixation to protect the blood clot and further bone damage potential because of increased activity of the animal samples after the first week of study. Another flaw is that the rabbit's tibial bone anatomy itself could not maintain the PRF membrane to be attached to the bone defect, therefore, with the cut blood vessels, PRF only has a paracrine effect. ${ }^{17}$

Although this study has shown significant results of PRF addition, however, there are some other inevitable drawbacks. The main problem is a small sample number that may not be an absolute indicator to prove the effectiveness of PRF. This study could be a preliminary study for a bigger sample study. Rabbit as an animal model may also not be the best choice, because a rabbit walks using its 4 legs, not like a human with only 2 legs. Another thing is that this study only analyzes bone healing histologically. Several methods like radiology, biochemical, biomechanical, and gene expression analysis have not been carried out.

In conclusion, this study shows that PRF given along with bone graft therapy can enhance the quality of defect fracture healing on a long bone. Future study about the PRF content that influences the fracture healing process needs further exploration.

\section{References}

1. Kanthan SR, Kavitha G, Addi S, Choon DSK, Kamarul T. Platelet-rich plasma (PRP) enhances bone healing in non-united critical-sized defects: A preliminary study involving rabbit models. Injury. 2011;42(8):782-9.

2. Mills LA, Simpson AHRW. The relative incidence of fracture non-union in the Scottish population (5.17 million): a 5-year epidemiological study. BMJ Open. 2013;3(2):e002276.

3. Lascombes P, Popkov D, Huber H, Haumont T, Journeau P.Classification of complication after progressive long bone lengthening: proposal of a new classification. Orthop Traumatol Surg Res.2012;98(6):629-37

4. Hasler CC, Krieg AH. Current concept of leg lenghtening. J Child Orthop. 2012;6(2):89104

5. Kazemi D, Fakhrjou A, Dizaji VM, Alishahi MK. Effect of autologous platelet rich fibrin on the healing of experimental articular cartilage defect of the knee in an animal model. Biomed Res Int. 2014;2014:486436

6. Bagi CM, Berryman E, Moalli MR. Comparative bone anatomy of commonly used laboratory animals: implications for drug discovery. Comp Med.2011;61(1):7685

7. Department of Laboratory Animal Resources The University of Toledo. Guidelines for blood collection: rodents and rabbits. 2011 [Cited 2017 September 13] Available from: https://www.utoledo. edu/Guideline-for-Blood-CollectionRodents-and-Rabbits.pdf

8. Ehrenfest DMD, Bielecki T, Jimbo R, Barbé $\mathrm{G}$, Corso MD, Inchingolo F, et al. Do the fibrin architecture and leukocyte content influence the growth factor release of platelet concentrates? An evidence-based answer comparing a pure platelet-rich plasma (P-PRP) gel and a leukocyte- and platelet-rich fibrin (L-PRF). Curr Pharm Biotechnol. 2012;13(7):1145-52

9. Salkeld SL, Patron LP, Barrack RL, Cook $\mathrm{SD}$. The effect of osteogenic protein-1 on 
the healing of segmental bone defects treated with autograft or allograft bone. J Bone Joint Surg Am. 2001;83(6):803-16.

10. Leteve M, Passuti N. Current concepts in bone graft substitutes. New Journal of Glass and Ceramics. 2018;8(3):39-54

11. Pripatnanont $P, \quad$ Nuntanaranont T, Vongvatcharanon $S$, Phurisat K. The primacy of platelet rich fibrin on bone regeneration of various grafts in rabbit's calvarial defect. J Craniomaxillofac Surg. 2013;41(8):191-200.

12. Pastor MF, Floerkemeier $\mathrm{T}$, Witte $\mathrm{F}$, Nellesen J, Thorey F, Windhagen H, et al. Repetitive recombinant human bone morphogenetic protein 2 injection improve the callus microarchitecture and mechanical stiffness in a sheep model of distraction osteogenesis. Orthop Rev (Pavia). 2012;4(1):e13.

13. Miller MD, Thompson SR, Hart J. Miller's review of orthopaedics. $6^{\text {th }}$ Ed. Philadelphia: Elsevier Health Sciences;
2012. p.1-5

14. Venkataraman N, Bansal S, Bansal P, Narayan S. Dynamic of bone graft healing around implants. J Int Clin Dent Res Organ. 2015;7:40-7

15. Pluemsakunthai W, Kuroda S, Shimokawa $\mathrm{H}$, Kasugai S. A basic analysis of platelet-rich fibrin: distribution and release of plateletderived growth factor-BB. Inflammation and Regeneration. 2013;33(3):164-7.

16. He L, Lin Y, Hu X, Zhang Y, Wu H. A comparative study of platelet-rich fibrin (PRF) and platelet-rich plasma (PRP) on the effect of proliferation and differentiation of rat osteoblasts in vitro. Oral Surg Oral Med Oral Pathol Oral Radiol Endod. 2009;108(5):707-13

17. Faot F, Deprez S, Vandamme K, Camargos GV, Pinto N, Wouters J, et al. The effect of L-PRF membranes on bone healing in rabbit tibiae bone defect: micro-CT and biomarker results. Sci Rep. 2017;7:46452. 